\title{
EDUCAÇÃO ESPECIAL E FORMAÇÃO CONTINUADA DE PROFESSORES DE EDUCAÇÃO FÍSICA: UMA REVISÃO SISTEMÁTICA
}

\author{
EDUCACIÓN ESPECIAL Y FORMACIÓN CONTINUA DE PROFESORES DE \\ EDUCACIÓN FÍSICA: UNA REVISIÓN SISTEMÁTICA
}

\section{SPECIAL EDUCATION AND CONTINUING EDUCATION OF PHYSICAL EDUCATION TEACHERS: A SYSTEMATIC REVIEW}

\author{
Patrícia d'Azeredo ORLANDO-BACCIOTTI ${ }^{1}$ \\ Juliane Aparecida de Paula Perez CAMPOS ${ }^{2}$
}

RESUMO: A formação continuada dos profissionais da Educação Física, para atuarem na educação inclusiva, é uma possibilidade de oferecer subsídios para um trabalho mais assertivo. Portanto, este estudo objetivou identificar como se caracterizam as propostas de formação continuada, na perspectiva de um ensino que ofereça subsídios para o trabalho desses profissionais junto aos estudantes Público-Alvo da Educação Especial nas aulas de Educação Física. As informações foram coletadas a partir de Teses e Dissertações indexadas na Biblioteca Digital Brasileira de Teses e Dissertações (BDTD) e no Catálogo de Teses e Dissertações da CAPES. Após critérios de inclusão e exclusão, doze documentos foram escolhidos e lidos na totalidade e passaram por uma análise temática de abordagem qualitativa. Seis deles trouxeram informações sobre cursos de formação continuada elaborados, aplicados e/ou analisados pelo próprio pesquisador, e, nos outros, os pesquisadores objetivaram investigar os efeitos de cursos oferecidos por algum órgão, na formação e/ou na prática dos professores. Concluiu-se que os cursos de formação continuada oferecidos para professores de Educação Física estão trabalhando com definição de termos e conceitos, com elementos relacionados ao trabalho destes professores, com estratégias e instrumentos de ensino e aprendizagem, exemplos de atividades, possibilitando o desenvolvimento de novas estratégias e do repensar sobre suas práticas, visando atender às necessidades, promover a participação e a retenção dos alunos Público-Alvo da Educação Especial em suas aulas.

PALAVRAS-CHAVE: Formação continuada. Educação física. Educação especial. Capacitação.

RESUMEN: La formación continua de profesores de educación fisica es una posibilidad para ofrecer un trabajo competente en el ámbito de la educación inclusiva. Este estudio tuvo como objetivo identificar cómo se caracterizan las propuestas de educación continua, desde una enseñanza que ofrece bases para el trabajo con estudiantes de Educación Especial en

\footnotetext{
${ }^{1}$ Universidade Federal de São Carlos (UFSCar), São Carlos - SP - Brasil. Doutoranda no Programa de PósGraduação em Educação Especial. ORCID: https://orcid.org/0000-0002-9834-3161. E-mail: patricia.ccaer@gmail.com

2 Universidade Federal de São Carlos (UFSCar), São Carlos - SP - Brasil. Professora Associada do Departamento de Psicologia, Docente no curso de Licenciatura em Educação Especial e no Programa de PósGraduação em Educação Especial. ORCID: https://orcid.org/0000-0003-0789-808X. E-mail: jappcampos@gmail.com
} 
clases de educación física. La información se recopiló de la página web: Biblioteca Digital Brasileña de Tesis y Disertaciones. (BDTD) y del Catálogo de Tesis y Disertaciones de la Coordinación para la Mejora del Personal de Educación Superior (CAPES). Después de aplicar los criterios de inclusión y exclusión, doce documentos fueron seleccionados y leídos en su totalidad, sometiéndose a un análisis temático de enfoque cualitativo. Seis de ellos aportaron información sobre cursos de formación continua elaborados, aplicados y/o analizados por el propio investigador, en los demás, los investigadores tenían como objetivo indagar los efectos de los cursos ofrecidos por alguna institución, la formación y/o práctica de los profesores. Se concluyó que los cursos de formación continua ofrecidos a los profesores de educación física están trabajando con definición de términos y conceptos, con elementos relacionados con el trabajo de estos profesores, con estrategias e instrumentos y con ejemplos de actividades; permitiendo el desarrollo de nuevas estratégias docentes, repensando sobre sus prácticas y también motivando la búsqueda de una educación física que pueda satisfacer las necesidades y promover la participación y retención de los estudiantes de Educación Especial en sus clases.

PALABRAS CLAVE: Formación continua. Educación Física. Educación especial. Entrenamiento.

ABSTRACT: The continuing training of physical education professionals, to work in inclusive education, is a possibility to offer subsidies for a more confident job. Therefore, this study aimed to identify how the proposals for continuing education are characterized, from the perspective of a teaching that offers subsidies for the work of these professionals with students Target Audience of Special Education in physical education classes. The information was collected from theses and dissertations indexed in the Brazilian Digital Library of Theses and Dissertations (BDTD) and in the CAPES Thesis and Dissertations Catalogue. After applying the inclusion and exclusion criteria, and the twelve selected theses and/or dissertations were read in full and underwent a thematic analysis of qualitative approach. Six of them brought information about continuous training courses elaborated, applied and/or analyzed by the researcher himself, and in the others, the researchers aimed to investigate the effects of courses offered by some organ, the training and/or practice of teachers. It was concluded that the continuing training courses offered to physical education teachers are working with definition of terms and concepts, with elements related to the work of these teachers, with teaching strategies and instruments and with examples of activities, enabling the development of new teaching strategies, rethinking about their practices and also the search for a physical education that can meet the needs and promote the participation and retention of target public students of the Special Education in your classes.

KEYWORDS: Continuing education. Physical Education. Special education. Training.

\section{Introdução}

A questão da formação continuada no Brasil é contemporânea em termos de existência legal. Ela surgiu, de acordo com Galindo e Inforzato (2016), a partir de uma necessidade de aperfeiçoamento profissional e centrada em ações pontuais, desenvolvidas principalmente nas formas de treinamento e capacitação.

RIAEE - Revista Ibero-Americana de Estudos em Educação, Araraquara, v. 16, n. 2, p. 649-665, abr./jun. 2021. e-ISSN: 1982-5587 
No entanto, como lembram Bahia et al. (2018), hoje, gestores de Educação utilizam estratégias diferenciadas para sistematizar essas formações continuadas. Elas vão desde cursos de longo prazo, como programas lato sensu de pós-graduação, até palestras com uma carga horária mais reduzida.

O Ministério da Educação (MEC) define em suas Orientações Gerais da Rede Nacional de Formação Continuada de Professores de Educação Básica, que

[...] é preciso pensar a formação docente como momentos de um processo contínuo, de construção de uma prática docente qualificada e de afirmação da identidade, da profissionalidade e da profissionalização do professor (BRASIL, 1999, p. 17).

Na Lei n. 9.394, Lei de Diretrizes e Bases da Educação Nacional (LDB), também são citadas as medidas que possam incentivar a formação continuada de professores (BRASIL, 1996). Em seu artigo 63, parágrafo terceiro, cita que "a União, o Distrito Federal, os Estados e os Municípios, em regime de colaboração, deverão promover a formação inicial, a continuada e a capacitação dos profisssionais de magistério" (BRASIL, 1996, p. 23).

Tendo em vista a Educação Especial na perspectiva da Educação Inclusiva, as políticas e legislações (BRASIL, 2008; 2015) atuais destacam o acesso, participação e aprendizagem de estudantes Público-Alvo da Educação Especial ( $\mathrm{PAEE}^{3}$ ) em sistemas comuns de ensino. Segundo o documento da Base Nacional Comum Curricular (BNCC), a Educação Física, enquanto componente obrigatório a partir do Ensino Fundamental, deve participar desse processo e assegurar práticas pedagógicas inclusivas e adequadas às necessidades individuais dos estudantes PAEE (BRASIL, 2017).

Frente a este novo cenário, Falkenbach (2007) já argumentava que a formação inicial em Educação Física era pautada em fundamentos conteudistas e em técnicas didáticas, e tal fato poderia acarretar uma dificuldade dos profissionais dessa área para desenvolverem seus trabalhos frente à inclusão de alunos PAEE. Complementando, Rossi e Munster (2013) também apontam que na formação inicial, os profissionais da área da Educação Física recebem poucos subsídios para o trabalho com alunos PAEE, pois os currículos abrangem poucas disciplinas que abordam as variáveis compreendidas e necessárias para o planejamento e ações pedagógicas que contemplem a inclusão.

Portanto, ações de formação continuada entendidas como uma construção de conhecimento coletivo, que envolvem desde as necessidades históricas, as experiências de

${ }^{3}$ Considera-se Público-Alvo da Educação Especial (PAEE) os estudantes com deficiência, transtornos globais do desenvolvimento (TGD) e altas habilidades/superdotação, segundo a Política Nacional de Educação Especial na Perspectiva da Educação Inclusiva (BRASIL, 2008). 
vida pessoal e profissional, e os conhecimentos historicamente construídos, representam um caminho necessário no processo de preparação dos profissionais que atuarão com os estudantes PAEE (MARIN et al., 2011). Tais considerações reforçam os resultados encontrados por Boato, Sampaio e Silva (2012), que observaram em um estudo que parte dos professores de Educação Física não se sentiam capacitados para realizar suas ações com um estudante PAEE em suas aulas, e isso os levou à necessidade de buscar, junto às Secretarias de Ensino, cursos de capacitação e formação continuada ou espaços para discussão de assuntos referentes ao processo de inclusão com especialistas em Educação Especial.

Cruz (2008) realizou um estudo que objetivou acompanhar como um programa de formação continuada para professores de Educação Física poderia contribuir para o enfrentamento da proposta de inclusão escolar de estudantes que apresentavam necessidades educacionais especiais ${ }^{4}$. Nesse sentido, o autor comenta que a implementação desse tipo de programa pode aprimorar o instrumental desse professor para elaborar respostas às provocações lançadas pela proposta da inclusão escolar.

Percebe-se, então, que a formação continuada dos profissionais da área de educação física para atuarem diante dessa perspectiva de inclusão de estudantes PAEE nas aulas regulares apresenta-se como possibilidade de oferecer a esses professores recursos, conteúdos e caminhos para uma ação mais confiante e que atenda à diversidade de seus estudantes. Porém, faz-se necessária a reflexão sobre quais tipos de formação estão sendo usadas para referenciar a formação posterior do educador que já concluiu sua formação inicial em educação física.

Diante do exposto, o presente estudo teve como objetivo identificar como se caracterizam as propostas de formação continuada para professores de educação física, na perspectiva de um ensino que ofereça subsídios para o trabalho desses profissionais junto aos estudantes PAEE.

\section{Método}

Este estudo caracteriza-se como pesquisa bibliográfica, do tipo exploratório-descritiva, ou seja, como um procedimento metodológico importante na produção do conhecimento científico capaz de gerar achados e interpretações que servirão de ponto de partida para outras pesquisas (LIMA; MIOTO, 2007).

\footnotetext{
${ }^{4}$ Optou-se em manter os termos utilizados pelo autor no texto original. Em documentos posteriores este termo
} foi alterado para pessoa com deficiência (BRASIL, 2015) 
Considerando que em 2008 foi publicada a Política Nacional de Educação Especial na Perspectiva da Educação Inclusiva (BRASIL, 2008), e que essa publicação é um dos marcos normativos da Educação Especial no Brasil, para esse estudo foi realizado um levantamento de resumos de Teses e Dissertações indexadas na Biblioteca Digital Brasileira de Teses e Dissertações (BDTD) e no Catálogo de Teses e Dissertações da CAPES entre os anos de 2008 a 2019.

Após realizar uma consulta ao Thesaurus Brasileiro de Educação, foram eleitas as string que foram utilizadas na coleta dos dados. Foi utilizado, também, o operador booleano AND, a fim de ampliar os resultados das buscas, conforme orientam Koller, Paula Couto e Hohendorff (2014).

Durante os meses de julho e agosto de 2019 foram acessados o BDTD e o Catálogo de Teses e Dissertações da CAPES, considerando-se os seguintes termos nos títulos, resumos ou nas palavras-chave das teses ou das dissertações: "Capacitação" AND "Educação Física" AND "Inclusão"; "Capacitação" AND "Educação Física” AND "Educação Especial”; "Formação em serviço" AND "Educação Física" AND "Inclusão"; "Formação em Serviço" AND "Educação Física" AND "Educação Especial”; "Formação Continuada" AND “Educação Física” AND “Inclusão" e "Formação Continuada” AND “Educação Física” AND "Educação Especial".

Entre teses e dissertações, foram encontrados 83 trabalhos na BDTD e 116 no Catálogo de Teses e Dissertações da CAPES, totalizando 199 teses e/ou dissertações. Todos os dados obtidos foram armazenados para a continuação das análises. As teses e dissertações consideradas potencialmente relevantes foram submetidas à leitura de seus títulos e resumos por dois juízes, e houve a aplicação dos critérios de inclusão, que foram: I) estar relacionado a alguma formação posterior à formação inicial em Educação Física envolvendo a área da Educação Especial ou da Educação Física na perspectiva da Educação Inclusiva; II) que estivessem no idioma Português; III) que tivessem sido publicadas entre 2008 e 2019.

Os critérios de exclusão utilizados foram: I) Ocorrências repetidas; II) Não tivessem sido publicadas entre os anos de 2008 e 2019; III) Que não estivessem relacionadas com o propósito do presente estudo ou IV) Os que não puderam ser acessados na íntegra nas bases de dados da CAPES ou da BDTD, ou nos Repositórios das bibliotecas de suas respectivas Universidades e V) Os que não estavam redigidos em Língua Portuguesa.

Portanto, das 199 teses/dissertações encontradas, foram eliminadas 44 por serem duplicadas e 141 por não atenderem aos critérios de inclusão. Após essa primeira seleção, restaram 9 dissertações e 5 teses. 
Em uma segunda etapa, esses trabalhos foram lidos na íntegra a fim de se obterem informações relacionadas às propostas de formação continuada para professores de Educação Física, na perspectiva de um ensino que oferecesse subsídios para o trabalho desses profissionais junto aos estudantes PAEE.

No final desta segunda etapa foram elencados 12 trabalhos, sendo 4 teses e 8 dissertações, em síntese qualitativa para comporem esta revisão, conforme mostra a Figura abaixo.

Figura 1 - Fluxograma da primeira etapa da revisão- Número de Teses/Dissertações

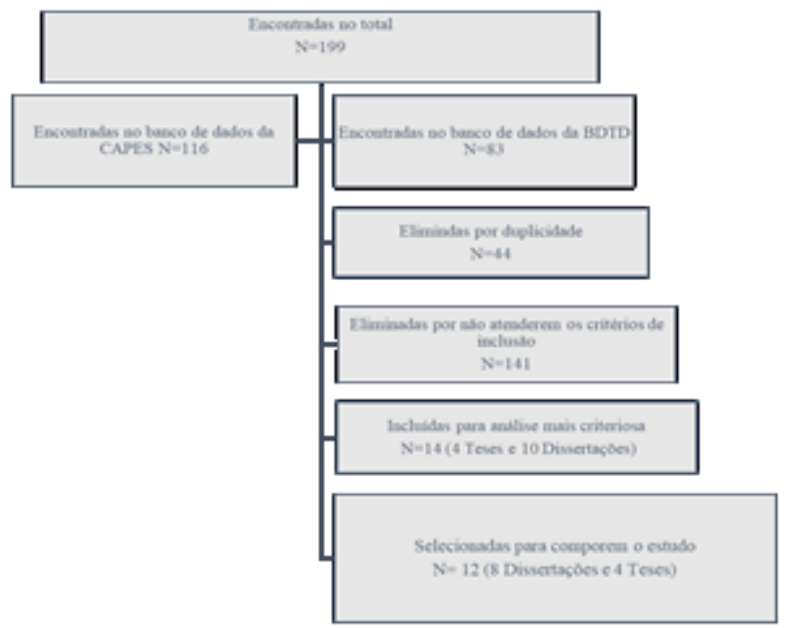

Fonte: Elaborado pelas autoras

Após essa etapa, foi realizada a extração dos dados dos estudos selecionados (COSTA; ZOLTOWSKI, 2014).

A interpretação dos dados foi realizada dentro de uma abordagem qualitativa, e para isso foi utilizada a análise temática para verificação dos dados obtidos, que, de acordo com Braun e Clarke (2006), serve para identificar, analisar e relatar padrões dentro dos dados, através de seis fases: i) Familiarização com os dados, onde serão anotados dados e ideias iniciais; ii) Geração de códigos iniciais, que é codificar dentro do conjunto de dados as características interessantes ao estudo; iii) Busca, que consiste no agrupamento dos códigos em temas potenciais; iv) Revisão, que é o mapeamento temático da análise; v) Nomeação de temas, onde serão feitas novas análises para refinar as especificidades de cada tema e nomeálos, e; vi) produção de relatórios, que é a última oportunidade para a análise, e a fase de realizar a relação entre a análise, a questão da pesquisa e a literatura.

\section{Resultados e discussão}


A partir da análise das dissertações e teses selecionadas, os resultados evidenciaram um maior número de trabalhos publicados no ano de 2017 e realizados por pesquisadores de Universidades Públicas. Além disso, seis trouxeram informações sobre cursos de formação continuada elaborados, aplicados e/ou analisados pelo próprio pesquisador. Os estudos e respectivos objetivos podem ser visualizados no quadro abaixo:

Quadro 1 - Estudos onde os pesquisadores tiveram uma ação ativa nos cursos de formação continuada

\begin{tabular}{|c|c|c|c|}
\hline $\begin{array}{l}\text { Tipo de } \\
\text { estudo }\end{array}$ & Ano & Autor & Objetivo geral \\
\hline Dissertação & 2011 & EFFGEN, A. P. S. & $\begin{array}{l}\text { Investigar possibilidades de articulação entre o } \\
\text { currículo escolar e a escolarização de alunos com } \\
\text { deficiência e TGD em processos de inclusão } \\
\text { escolar, a partir da instituição de espaços e tempos } \\
\text { de formação continuada e de ações colaborativas. }\end{array}$ \\
\hline Dissertação & 2012 & NASCIMENTO, S. F. & $\begin{array}{l}\text { Compreender as implicações de uma ação de } \\
\text { formação continuada na prática pedagógica dos } \\
\text { professores de educação física no processo de } \\
\text { inclusão. }\end{array}$ \\
\hline Tese & 2015 & FIORINI, M. L. S. & $\begin{array}{l}\text { Planejar, aplicar e avaliar um programa de } \\
\text { formação continuada para professores de educação } \\
\text { física visando proporcionar acesso aos recursos e } \\
\text { estratégias de tecnologia assistiva para a inclusão } \\
\text { escolar de alunos com deficiência e alunos com } \\
\text { autismo. }\end{array}$ \\
\hline Tese & 2015 & TOLOI, G. G & $\begin{array}{l}\text { Planejar, aplicar e avaliar um programa de } \\
\text { formação para professores de educação física, } \\
\text { visando à inclusão educacional de alunos com } \\
\text { deficiência, por meio da tecnologia assistiva. }\end{array}$ \\
\hline Tese & 2016 & MAHL, E. & $\begin{array}{l}\text { Analisar a contribuição de um programa de } \\
\text { formação continuada para professores de educação } \\
\text { física na construção e reconstrução de saberes } \\
\text { sobre inclusão escolar. }\end{array}$ \\
\hline Tese & 2017 & OLIVEIRA, A. C. S. & $\begin{array}{l}\text { Implementar e avaliar um programa de formação } \\
\text { pela via colaboração para professores de educação } \\
\text { física. }\end{array}$ \\
\hline
\end{tabular}

Fonte: Dados da pesquisa

Esses trabalhos tiveram uma participação ativa dos pesquisadores em relação aos cursos de formação continuada, que foram elaborados após identificação das necessidades de cada população pertencente ao respectivo estudo. Essas necessidades foram levantadas a partir de grupos focais, filmagens, observações, registros em diários de campo, entrevista e questionários.

A partir disso, os cursos de formação continuada envolveram formações teóricas e práticas, e abordaram temas como definições sobre PAEE, Inclusão, Tecnologia Assistiva, Educação Física e Deficiência, aspectos relacionados à família e às questões administrativo- 
escolares, tutoria de estudantes, ensino colaborativo e coensino, currículo e avaliação. Esses conteúdos foram trabalhados em um número de no mínimo de cinco, e no máximo vinte encontros, que variaram entre si, com cargas horárias que também variaram entre seis e cento e vinte horas.

O eixo principal desses estudos foi o trabalho colaborativo, realizado em sua maioria por meio de conversas, ações reflexivas sobre as práticas pedagógicas, discussões sobre as estratégias utilizadas nas aulas e planejamentos das aulas de forma colaborativa entre pesquisador e professor, ao longo dos encontros.

A partir dos objetivos propostos, de elaboração, aplicação e avaliação dos Cursos de Formação Continuada, os trabalhos apresentados trouxeram algumas conclusões que podem ser observadas no Quadro 2.

Quadro 2 - Conclusões dos estudos com ação ativados pesquisadores nos cursos de formação continuada.

\begin{tabular}{|c|l|l|l|}
\hline $\begin{array}{c}\text { Tipo de } \\
\text { estudo }\end{array}$ & Ano & \multicolumn{1}{|c|}{ Autor } & \multicolumn{1}{|c|}{$\begin{array}{c}\text { Conclusões acerca dos Cursos de Formação } \\
\text { Continuada }\end{array}$} \\
\hline Dissertação & 2011 & EFFGEN, A. P. S. & $\begin{array}{l}\text { Entendeu-se que a Formação Continuada pode ser } \\
\text { uma ação que pode apontar novas possibilidades de } \\
\text { trabalho pedagógico com alunos PAEE na escola de } \\
\text { ensino comum. }\end{array}$ \\
\hline Dissertação & 2012 & NASCIMENTO, S. F. & $\begin{array}{l}\text { Colocou em evidência a importância desse tipo de } \\
\text { formação, em que, na companhia de seus colegas de } \\
\text { trabalho, permitia maior troca de experiência, } \\
\text { estimula a prática reflexiva, c colabora para que o } \\
\text { professor encontre respostas às suas reais } \\
\text { necessidades. }\end{array}$ \\
\hline Tese & 2015 & FIORINI, M. L. S. & $\begin{array}{l}\text { Considerar o contexto de trabalho e as demandas } \\
\text { dos professores são fatores primordiais para um } \\
\text { bom resultado na elaboração e aplicação de cursos } \\
\text { de formação continuada. }\end{array}$ \\
\hline Tese & 2015 & TOLOI, G. G & $\begin{array}{l}\text { Houve uma colaboração efetiva para a formação do } \\
\text { professor em busca da Inclusão, pois, verificou-se } \\
\text { que, após o curso, foram utilizadas estratégias e } \\
\text { recursos adaptados às necessidades específicas dos } \\
\text { alunos PAEE. }\end{array}$ \\
\hline Tese & 2016 & MAHL, E. & $\begin{array}{l}\text { Concluiu-se que os aspectos trabalhados no Curso } \\
\text { de Formação Continuada, deram contribuiçoses } \\
\text { significativas para as ações cotidianas dos } \\
\text { participantes do estudo. }\end{array}$ \\
\hline OLIVEIRA, A. C. S. & $\begin{array}{l}\text { Os professores avaliaram de forma positiva os } \\
\text { Programa (Curso de formação continuada) e, } \\
\text { conseguiram compreender é necessário para que as } \\
\text { práticas pedagógicas, as modificações e ajustes } \\
\text { metodológicos sejam realizados para a efetivação } \\
\text { da inclusão escolar em direção à participação de } \\
\text { todos os alunos. }\end{array}$ \\
\hline
\end{tabular}

Fonte: Dados da pesquisa 
Nos outros seis trabalhos, observou-se que os pesquisadores apresentaram cursos oferecidos por órgãos, como Diretorias Regionais de Ensino, Secretarias de Educação Municipais e/ou Projetos de Extensão de Universidades, com o objetivo de investigar os efeitos desses cursos na formação e/ou na prática dos professores.

Esses estudos não tiveram uma participação ativa dos pesquisadores em relação aos Cursos de Formação Continuada. Eles foram oferecidos pelos órgãos mencionados, em formas de Oficinas Pedagógicas, Curso de Especialização e/ou por Grupo Operativo de Formação. Seus objetivos podem ser visualizados com maior clareza no Quadro 3.

Quadro 3 - Estudos que investigaram os efeitos cursos oferecidos por algum órgão

\begin{tabular}{|c|c|c|l|}
\hline $\begin{array}{c}\text { Tipo de } \\
\text { estudo }\end{array}$ & Ano & \multicolumn{1}{|c|}{ Autor } & \multicolumn{1}{c|}{ Objetivo geral } \\
\hline Dissertação & 2009 & BONATO, N. A. M. & $\begin{array}{l}\text { Verificar a ocorrência de cursos de formação } \\
\text { continuada na área de educação Física com a temática } \\
\text { inclusão escolar, quantos professores participaram, } \\
\text { níveis de escolaridade que atuam, e tipo de } \\
\text { repercussão na prática escolar. }\end{array}$ \\
\hline Dissertação & 2013 & SOUZA, F. A. & $\begin{array}{l}\text { Conhecer e analisar a prática pedagógica inclusiva } \\
\text { experimentada pelos professores de educação física na } \\
\text { escola, durante uma ação de formação continuada. }\end{array}$ \\
\hline Dissertação & 2017 & LACERDA, L. C. Z. & $\begin{array}{l}\text { Analisar se, e de que forma experiência da formação } \\
\text { continuada vivenciada ao longo do processo foi } \\
\text { traduzida nas escolas onde atuavam. }\end{array}$ \\
\hline Dissertação & 2017 & PETERLE, L. L. & $\begin{array}{l}\text { Compreender as particularidades, os desafios e as } \\
\text { possibilidades postas às professoras/ gestoras da área } \\
\text { de Educação Física e a Educação Especial e analisar o } \\
\text { processo de formação continuada na perspectiva da } \\
\text { inclusão. }\end{array}$ \\
\hline Dissertação & 2017 & SOBRINHO, J. M. & $\begin{array}{l}\text { Discutir a formação continuada em serviço promovida } \\
\text { pela secretaria municipal de educação de Natal. }\end{array}$ \\
\hline Dissertação & 2019 & NUNES, F. S. F. & $\begin{array}{l}\text { Analisar a compreensão dos professores acerca dos } \\
\text { contributos da formação continuada do projeto portas } \\
\text { abertas para a inclusão }\end{array}$ \\
\hline
\end{tabular}

Fonte: Dados da pesquisa

Esses cursos de formação continuada envolveram formações teóricas e práticas, e abordaram temas que variaram desde disciplinas de metodologia de pesquisa, diversidade, ensino colaborativo, inclusão, legislação, Libras, Desenho Universal de Aprendizagem (DUA), autismo, Atendimento Educacional Especializado (AEE), políticas públicas e gestão, até disciplinas mais específicas da área de Educação Física, como esportes adaptados, jogos sensoriais e cooperativos e educação física para pessoa com deficiência. Foi possível observar que esses cursos tiveram uma duração que variou entre vinte e duzentos e sessenta horas.

Para o levantamento dos dados que foram utilizados na investigação dos efeitos destes cursos, na formação e/ou na prática dos professores, foram utilizados questionários, 
entrevistas, observações, as avaliações realizadas nos cursos, e as atividades e trabalhos de conclusão de curso denominados Trabalhos Acadêmicos, que foram considerados narrativas escritas em um dos trabalhos.

Após essa investigação esses trabalhos trouxeram algumas conclusões que podem ser observadas no Quadro 4.

Quadro 4 - Estudos que buscaram investigar os efeitos cursos oferecidos por algum órgão

\begin{tabular}{|c|c|c|l|}
\hline $\begin{array}{c}\text { Tipo de } \\
\text { estudo }\end{array}$ & Ano & Autor & $\begin{array}{l}\text { Conclusões acerca dos Cursos de Formação } \\
\text { Continuada }\end{array}$ \\
\hline Dissertação & 2009 & BONATO, N.A.M. & $\begin{array}{l}\text { A formação do professor se faz uma condição } \\
\text { impar para viabilizar mudanças significativas } \\
\text { para uma educação igualitária e de qualidade } \\
\text { para todos os alunos. }\end{array}$ \\
\hline Dissertação & 2013 & SOUZA, F.A. & $\begin{array}{l}\text { Sinalização positiva para a formação de } \\
\text { professores para a educação básica na } \\
\text { perspectiva da inclusão e uma importante } \\
\text { ferramenta a ser utilizadas pelas redes de } \\
\text { ensino como alternativa metodológica. }\end{array}$ \\
\hline Dissertação & 2017 & LACERDA, L.C.Z. & $\begin{array}{l}\text { Início de uma reflexão dos participantes quanto } \\
\text { suas práticas, inovações, maior embasamento } \\
\text { teórico, maior articulação entre experiências e } \\
\text { necessidades cotidianas e aumento do diálogo } \\
\text { crítico-reflexivo. }\end{array}$ \\
\hline Dissertação & 2017 & PETERLE, L.L. & $\begin{array}{l}\text { Ficou evidente que a maioria dos participantes } \\
\text { reconheceu a importância da Formação } \\
\text { Continuada, e caracterizam-na como uma } \\
\text { oportunidade para trocar experiências e receber } \\
\text { informações. }\end{array}$ \\
\hline Dissertação & 2017 & SOBRINHO, J. M. & $\begin{array}{l}\text { Foi um importante lócus de pesquisa sobre } \\
\text { formação docente e inclusão. }\end{array}$ \\
\hline Dissertação & 2019 & NUNES, F.S.F. & $\begin{array}{l}\text { Os cursos exprimiram princípios e dimensões } \\
\text { fomentadoras da constituição de uma escola } \\
\text { verdadeiramente inclusiva. }\end{array}$ \\
\hline
\end{tabular}

Fonte: Dados da pesquisa

Como aspectos gerais observou-se que os 12 trabalhos que fizeram parte dessa revisão atribuíram o termo Formação Continuada para referenciar os cursos aplicados, avaliados e/ou investigados. Porém, percebe-se que mesmo todos trazendo o termo "formação continuada" para denominar os cursos apresentados, ainda há uma mistura de termos, pois em determinados momentos o curso era chamado de capacitação, encontros de formação ou de formação em serviço.

Altenfelder (2005) afirma que essa confusão de conceitos entre treinamento, reciclagem, capacitação e formação continuada é algo que realmente é apresentado nas pesquisas da área. Em relação à metodologia, as pesquisas foram definidas como: colaborativa, reflexiva, descritiva, pesquisa-ação, pesquisa exploratória e estudo de caso, 
sendo que "Estudo de Caso" foi o método predominante, e apareceu em três estudos, sendo eles, Bonato (2009), Sobrinho (2017) e Nunes (2019). A abordagem qualitativa foi a mais utilizada para relatar os dados encontrados nos estudos, aparecendo em seis, dos doze estudos analisados.

O conteúdo trabalhado nesses cursos também nos ajuda a entender como os cursos estão acontecendo e quais são as informações que estão sendo transmitidas aos professores que deles participam. A partir da leitura dos trabalhos, e com base em Braun e Clarke (2006), foram nomeados quatro grandes temas. Eles estão descritos no quadro 5 e, a partir da definição deles, foram elencados os subtemas trabalhados, que mostram de maneira mais criteriosa os conteúdos que fizeram parte dos cursos de formação continuada:

Quadro 5 - Conteúdos trabalhados nos Cursos de formação continuada analisados

\begin{tabular}{|c|c|c|c|}
\hline $\begin{array}{l}\text { Definição de termos e } \\
\text { conceitos sobre }\end{array}$ & $\begin{array}{l}\text { Elementos } \\
\text { relacionados ao } \\
\text { trabalho do } \\
\text { professor }\end{array}$ & $\begin{array}{c}\text { Estratégias e } \\
\text { Instrumentos de } \\
\text { Ensino }\end{array}$ & $\begin{array}{c}\text { Exemplos de } \\
\text { Atividades } \\
\text { para as aulas } \\
\text { de Educação } \\
\text { Física } \\
\end{array}$ \\
\hline Educação Especial & Família & Tutoria de alunos & $\begin{array}{c}\text { Bocha } \\
\text { Adaptada }\end{array}$ \\
\hline $\begin{array}{c}\text { Deficiências (física, } \\
\text { intelectual, auditiva, visual e } \\
\text { múltiplas) }\end{array}$ & Gestão Escolar & $\begin{array}{l}\text { Desenho Universal de } \\
\text { acessibilidade }\end{array}$ & Jogos sensoriais \\
\hline $\begin{array}{l}\text { Autismo, Transtorno Global } \\
\text { do Desenvolvimento, Altas } \\
\text { habilidades e superdotação }\end{array}$ & $\begin{array}{l}\text { Elementos } \\
\text { relacionados à } \\
\text { Inclusão }\end{array}$ & Planejamento de Ensino & $\begin{array}{c}\text { Jogos } \\
\text { Cooperativos }\end{array}$ \\
\hline $\begin{array}{c}\text { História da Pessoa com } \\
\text { Deficiência }\end{array}$ & Políticas Públicas & Tecnologia Assistiva & - \\
\hline Diversidade & Educação X Saúde & $\begin{array}{l}\text { Instrumentos de } \\
\text { Avaliação }\end{array}$ & - \\
\hline Acessibilidade & - & $\begin{array}{c}\text { Consultoria colaborativa } \\
\text { e Coensino }\end{array}$ & - \\
\hline $\begin{array}{l}\text { Atendimento Educacional } \\
\text { Especializado }\end{array}$ & - & Adaptações Curriculares & - \\
\hline Educação Física Adaptada & - & $\begin{array}{l}\text { Plano de Ensino } \\
\text { Individualizado }\end{array}$ & - \\
\hline- & - & LIBRAS & - \\
\hline
\end{tabular}

Fonte: Elaborado pelas autoras

O primeiro tema levantado, que tratou sobre definições de termos e conceitos, nos demonstra que os conteúdos trabalhados nos cursos de capacitação trazem uma bagagem histórica e conceitual importante para a sensibilização dos professores sobre os aspectos que envolvem a inclusão dos estudantes PAEE nas aulas de Educação Física, o que corrobora com o que traz Marin et al. (2011), que enxergam a formação continuada como uma construção de conhecimento coletivo que envolve desde as necessidades históricas, as experiências de vida 
pessoal e profissional, e que representa um caminho necessário no processo de preparação dos profissionais que atuarão com os estudantes PAEE.

Percebe-se no segundo grande tema levantado que existe uma preocupação com o trabalho de todos aqueles que estão de alguma maneira envolvidos no processo de ensino e aprendizagem dos estudantes PAEE. Esses elementos estão relacionados, por exemplo, à família, gestão escolar, saúde e/ou políticas públicas.

No terceiro tema, observa-se a preocupação com as estratégias e instrumentos de ensino, como o coensino e a tutoria de alunos, que podem ser considerados estratégias que proporcionam uma melhor participação dos estudantes com deficiências nas aulas de Educação Física, como afirma Orlando (2010). Já no quarto tema levantado, exemplos de atividades para as aulas, são mostradas estratégias com esportes e jogos, que podem ser utilizadas pelos professores nas aulas, com vistas a estimular a participação e a retenção de todos os estudantes.

Os saberes propostos e discutidos nos programas de formação continuada tiveram, ao mesmo tempo, conceitos e teorias tradicionais, como: o que é inclusão, definição das características das deficiências, assim como trouxeram informações atualizadas, por exemplo, o Desenho Universal de Aprendizagem, que tem sido estudado atualmente por autores como Oliveira, Munster e Gonçalves (2019).

Os dados coletados mostraram que os conteúdos trabalhados nos cursos trouxeram contribuições significativas para as ações cotidianas dos participantes. Isso pode diminuir a dificuldade dos professores que não sentem que somente a formação inicial dá subsídios para um trabalho que atenda a demanda da diversidade nas aulas, como apontam Rossi e Munster (2013).

Foi possível observar também que, para promover um curso de formação continuada, elementos como o conhecimento do contexto em que o curso será aplicado, conhecimento prévio das necessidades e experiências dos participantes, e das demandas apresentadas pelos professores, são importantes, o que foi apontado por Fiorini (2015).

A sensibilização para o desenvolvimento de um trabalho colaborativo entre professores de Educação Física, professores do Atendimento Educacional Especializado, gestores, secretarias e diretorias regionais e estadual de educação e pesquisadores, também foi algo que se mostrou importante para o trabalho dentro da área, como citado por Mahl (2016).

\section{Considerações finais}

RIAEE - Revista Ibero-Americana de Estudos em Educação, Araraquara, v. 16, n. 2, p. 649-665, abr./jun. 2021. e-ISSN: 1982-5587 
Levando-se em consideração o fato de que muitas vezes os professores de Educação Física não se sentem capacitados para atender a diversidade presente em uma turma, muitas vezes devido a uma formação inicial frágil, os cursos de formação continuada mostraram ser uma importante ação para promover a reflexão das práticas pessoais, trazendo estratégias diferenciadas para que esses profissionais possam analisar, refletir e se posicionar sobre o que poderiam e deveriam fazer enquanto docentes que acreditam na inclusão.

Observa-se uma variedade entre os tipos de ações formativas, que se apresentam na forma de parceria entre professor e pesquisador para desenvolvimento de estratégias de ensino ou em parcerias junto às Diretorias/Secretarias de Educação, encontros semanais ou quinzenais para transmissão de conteúdo, ou então a promoção de espaços onde são discutidas e estudadas as ações desses professores sobre suas práticas.

Para que ações como essas, de oferta e de participação dos professores nos cursos de formação continuada, sejam efetivadas, observou-se a importância de um movimento de ações políticas e investimentos na formação desses educadores, pois, foi observado que os professores reconheceram sua importância na busca de garantias e de ofertas de oportunidades para todos os estudantes, sendo eles PAEE ou não.

Além disso, a interlocução entre as Universidades, pesquisadores, secretarias e professores pode favorecer a busca por conhecimentos que unam teorias e práticas das redes de ensino, efetivando-se como uma oportunidade de troca de experiências tanto de instrumentos como de estratégias de ensino.

Esses cursos também possuíram cargas horárias que variaram bastante, porém, mesmo aqueles com cargas horárias mais reduzidas tiveram uma avaliação positiva pelos seus participantes.

Conclui-se que os cursos de formação continuada de professores, sejam eles parte das políticas públicas, das pesquisas, ou das Secretarias/Diretorias de Educação, estão possibilitando que os docentes possam desenvolver novas estratégias de ensino, o repensar de suas práticas e também buscarem um trabalho mais assertivo, que possa atender às necessidades e promover a participação e a retenção dos estudantes Público-Alvo da Educação Especial em suas aulas.

\section{REFERÊNCIAS}


ALTENFELDER, A. H. Desafios e tendências em formação continuada. Constr. psicopedag., v. 13, n. 10, 2005. Versão impressa. ISSN 1415-6954. Disponível em: http://pepsic.bvsalud.org/scielo.php?script=sci_abstract\&pid=S1415-69542005000100004. Acesso em: 02 nov. 2019.

BAHIA, C. S. B. et al. Continuing education of physical education teachers: pedagogical actions by the regional education board of Ilhéus. Journal of Physical Education., Maringá, v. 29, e2961, 2018. DOI: https://doi.org/10.4025/jphyseduc.v29i1.2961

BOATO, E. M. SAMPAIO, T. M. V. SILVA, J. V. P. Capacitação de professores para inclusão de pessoas deficientes nas aulas de educação física. Motricidade, v. 8, n. supl. 2, p. 891-900, 2012. Disponível em: https://www.redalyc.org/pdf/2730/273023568113.pdf. Acesso em: 07 jun. 2019.

BONATO, N. A. M. Inclusão escolar: um estudo da formação continuada dos professores de Educação Física na cidade de Araraquara - SP. Orientadora: Luci Pastor Manzoli. 2009. 143 f. Dissertação (Mestrado) - Faculdade de Ciências e Letras de Araraquara, Universidade Estadual Paulista, Araraquara, SP, 2009. Disponível em: bdtd.ibict.br/vufind/Record/UNSP_313847b8762ec54351916763ac858528. Acesso em: 13 set. 2019.

BRASIL. Lei n. 13.146, de 6 de julho de 2015. Institui a Lei Brasileira de Inclusão da Pessoa com Deficiência (Estatuto da Pessoa com Deficiência). Brasília, DF, 07 jul. 2015. Disponível em: http://www.planalto.gov.br/Ccivil_03/_Ato2015-2018/2015/Lei/L13146.htm. Acesso em: 09 jul. 2020.

BRASIL. Lei n. 9.394, de 20 de dezembro de 1996. Lei de Diretrizes e Bases da Educação Nacional. Diário Oficial da União: Seção 1, Brasília, DF, n. 248, p. 27833, 23 dez. 1996. PL $1258 / 1988$

BRASIL. Ministério da Educação. Base Nacional Comum Curricular (BNCC). Educação é a Base. Brasília, MEC/CONSED/UNDIME, 2017. Disponível em: $\mathrm{http}$ ///basenacionalcomum.mec.gov.br/images/BNCC EI EF 110518 versaofinal site.pdf. Acesso em: 02 jun. 2020.

BRASIL. Ministério da Educação. Política Nacional de Educação Especial na Perspectiva da Educação Inclusiva. Brasília: MEC/SECADI, 2008.

BRASIL. Ministério de Educação e Cultura. Secretaria de educação Fundamental.

Referenciais para Formação de Professores. Brasília, DF: MEC, 1999.

BRAUN, V.; CLARKE, V. Using thematic analysis in psychology. Qualitative Research in Psychology, v. 3, p. 77-101, 2006.

COSTA, A. B.; ZOLTOWSKI, A. P. C. Como escrever um artigo de revisão sistemática. In: KOLlER, S. H.; COUTO, M. C. P. P.; HOHENDORFF, J. V. (Org.). Métodos de pesquisa: manual de produção científica. Porto Alegre, RS: Penso, 2014. p. 55-70.

CRUZ, G. C. Formação Continuada de professores de Educação Física em ambiente escolar inclusivo. Orientador: Julio Romero Ferreira. 2005. 229 f. Tese (Doutorado) -

RIAEE - Revista Ibero-Americana de Estudos em Educação, Araraquara, v. 16, n. 2, p. 649-665, abr./jun. 2021. e-ISSN: 1982-5587 
Faculdade de Educação Física, Universidade Estadual de Campinas, Campinas, SP. Disponível em: http://www.repositorio.unicamp.br/handle/REPOSIP/274958. Acesso em: 13 set. 2019.

EFFGEN, A. P. S. Educação Especial e Currículo Escolar: possibilidades nas práticas pedagógicas cotidianas. Orientadora: Denise Meyrelles de Jesus. 2011. 227 f. Dissertação (Mestrado em Educação) - Universidade Federal do Espírito Santo, Vitória, 2011. Disponível em: http://bdtd.ibict.br/vufind/Record/UFES_2b91519f640ea52c4454b05610a5eb00. Acesso em: 13 set. 2019.

FALKENBACH, A. P. A questão da integração e da inclusão nas aulas de Educação Física. Lecturas, Educación Física y Deportes, Buenos Aires, ano 11, n. 106, mar. 2007.Disponível $\mathrm{em}$ : http://www.efdeportes.com/efd106/a-questao-da-integracao-e-da-inclusaonas-aulas-deeducacao-fisica.htm. Acesso em: 17 mar. 2015.

FIORINI, M. L. S. Formação continuada do professor de Educação Física em tecnologia assistiva visando a inclusão. Orientador: Eduardo José Manzini. 2015. 155 f. Tese (Doutorado) - Faculdade de Filosofia e Ciências, Universidade Estadual Paulista, Marília, 2015. Disponível em: http://hdl.handle.net/11449/123891. Acesso em: 30 abr. 2019.

GALINDO, C. J.; INFORZATO, E. C. Formação de professores: impasses, contextos e perspectivas. Revista on line de Política e Gestão Educacional, Araraquara, v. 20, n. 03, p. 463-477, 2016. DOI: http://dx.doi.org/10.22633/rpge.v20.n3.9755

KOLLER, S. H.; DE PAULA COUTO, M. C. P.; HOHENDORFF, J. V. (Org.). Manual de produção científica. Porto Alegre: Penso, 2014. Disponível em:

https://www.biosanas.com.br/uploads/outros/artigos_cientificos/18/6505082c2a7c23986651c 7b1f7a4a92e.pdf. Acesso em: 02 nov. 2019.

LACERDA, L. C. Z. Formação continuada de professores e gestores: o programa REDEFOR educação especial e inclusiva em foco. Orientador: Renata Portela Rinaldi. 2017. 209 f. Dissertação (Mestrado em Educação) - Faculdade de Ciências e Tecnologia, Universidade Estadual paulista, Presidente Prudente, 2017. Disponível em: http://bdtd.ibict.br/vufind/Record/UNSP_857ce0a8b7c3c1f3bda0fce70fa0788b. Acesso em: 13 set. 2019.

LIMA, T. C. S.; MIOTO, R. C. T. Procedimentos metodológicos na construção do conhecimento científico: a pesquisa bibliográfica. Revista katálysis, Florianópolis, v. 10, p. 37-45, 2007. DOI: http://dx.doi.org/10.1590/S1414-49802007000300004

MAHL, E. Programa de formação continuada para professores de Educação Física: possibilidades para a construção de saberes sobre a inclusão de alunos com deficiência. Orientadora: Fátima Elisabeth Denari. 2016. 268 f. Tese (Doutorado em Educação Especial) Universidade Federal de São Carlos, São Carlos, 2016. Disponível em: http://bdtd.ibict.br/vufind/Record/SCAR_b7a53580bc52b3372fdcb9fdf4aab24a. Acesso em: 13 set. 2019.

MARIN, E. C. et al. Formação continuada em educação física: relação entre mundo do trabalho, políticas educacionais e educação. Movimento (ESEFID/UFRGS), Porto Alegre, p. 
259-278, jun. 2011. ISSN 1982-8918. Disponível em:

https://seer.ufrgs.br/Movimento/article/view/16670/13142. Acesso em: 02 nov. 2019.

NASCIMENTO, S. F. Formação continuada de professores de educação física na perspectiva da inclusão. Orientador: José Francisco Chicon. 2012. 128 f. Dissertação (Mestrado em Educação Física) - Centro de Educação Física e Desportos, Universidade Federal do Espírito Santo, Vitória, 2012. Disponível em:

http://bdtd.ibict.br/vufind/Record/UFES_5743fed2eafca9016b9b0358d0f5bc8e. Acesso em: 13 set. 2019.

NUNES, F. S. F. Formação de professores de educação física para a educação inclusiva: práticas corporais para crianças autistas. Orientadora: Morgana de Fátima Agostini Martin. 2019. 221 f. Tese (Doutorado em Educação) - Faculdade de Ciências Exatas e Tecnologia, Universidade Federal da Grande Dourados, Dourados, 2019. Disponível em:http://bdtd.ibict.br/vufind/Record/UFGD-2_98574e4acb16c4cace3ec5de7db10289. Acesso em: 13 set. 2019.

OLIVEIRA, A. C. S. Formação continuada na perspectiva colaborativa: subsídios para inclusão nas aulas de educação física. Orientadora: Maria da Piedade Resende da Costa. 2017. 200 f. Tese (Doutorado em Educação Especial) - Universidade Federal de São Carlos, São Carlos, 2017. Disponível em:

https://repositorio.ufscar.br/bitstream/handle/ufscar/9847/TESE\%20ACSO.pdf?sequence=3\& isAllowed=y. Acesso em: 6 mar. 2020.

OLIVEIRA, A. R. P.; MUNSTER, M. A.; GONCALVES, A. G. Desenho Universal para Aprendizagem e Educação Inclusiva: uma revisão sistemática da literatura internacional. Revista brasileira de educação especial, Bauru, v. 25, n. 4, p. 675-690, dez. 2019. DOI: https://doi.org/10.1590/s1413-65382519000400009

ORLANDO, P. A. O colega tutor de alunos com deficiência visual nas aulas de Educação Física. Orientadora: Fátima Elisabeth Denari. 2010. 75 f. Dissertação (Mestrado em Educação Especial) - Universidade Federal de São Carlos, São Carlos, 2010.

PETERLE, L.L. Formação, gestão e inclusão: a experiência da educação física no município de Viana. Orientador: José Francisco Chicon. 2017. 133 f. Dissertação (Mestrado em Educação Física) - Centro de Educação Física e Desportos, Universidade Federal do Espírito Santo, Vitória, 2017. Disponível em:

http://bdtd.ibict.br/vufind/Record/UFES_3926faa9b1376c92f6a8b25df4b986d8. Acesso em: 13 set. 2019.

ROSSI, P.; MUNSTER, M. A. Formação profissional em Educação Física Adaptada: um estudo de caso. In: ENCONTRO DA ASSOCIAÇÃO BRASILEIRA DE PESQUISADORES EM EDUCAÇÃO ESPECIAL, 8., 2013, Londrina. Anais [...]. Londrina, PR: Universidade Estadual de Londrina, 2013.

SOBRINHO, J.M. Educação física escolar, formação continuada em serviço e inclusão: um diálogo com a diversidade. Orientadora: José Pereira de Melo. 2017. 113 f. Dissertação (Mestrado em Educação) - Centro de Educação, Universidade Federal do Rio Grande do Norte, Natal, 2017. Disponível em: 
http://bdtd.ibict.br/vufind/Record/UFRN_30d29e98ea59f9afd5ce1e8a1db93d81. Acesso em: 13 set. 2019.

SOUZA, F. A. Formação, educação física e inclusão: compreendendo os processos inclusivos. Orientador: José Francisco Chicon. 2013. 112 f. Dissertação (mestrado em Educação Física) - Centro de Educação Física e Desporto da Universidade Federal do Espírito Santo, Vitória. 2013.

TOLOI, G. G. Formação de professores de educação física para inclusão educacional usando tecnologia assistiva. Orientador: Eduardo José Manzini. 2015. 212 f. Tese (Doutorado) - Universidade Paulista Júlio de Mesquita Filho, Faculdade de Filosofia e Ciências, 2015. Disponível em:

http://bdtd.ibict.br/vufind/Record/UNSP_f1fff02b36842baafc44e6529cc1b986. Acesso em: 13 set. 2019.

\section{Como referenciar este artigo}

ORLANDO-BACCIOTTI, P. D.; CAMPOS, J. A. P. P. Educação especial e formação continuada de professores de Educação Física: uma revisão sistemática. Revista IberoAmericana de Estudos em Educação, Araraquara, v. 16, n. 2, p. 649-665, abr.jun. 2021. eISSN: 1982-5587. DOI: https://doi.org/10.21723/riaee.v16i2.13449

Submetido em: 16/03/2020

Revisões requeridas em: 03/05/2020

Aprovado em: $15 / 08 / 2020$

Publicado em: 01/02/2021 